\title{
Ultrasound assessment of the external occipital protuberance in young adults. Clinical implications
}

\author{
Adrián Benito Domingo ${ }^{1}$ Alberto García Godino ${ }^{1}$ \\ 1 Sannus Clinic, Pozuelo de Alarcón, Madrid, Spain \\ 2 Recuperatebien s.I., Madrid, Spain \\ Address for correspondence Adrián Benito Domingo, PhD, Sannus \\ Clinic, Av. Juan Antonio Samaranch Torelló, 8, 28223 Pozuelo de \\ Alarcón, Madrid, Spain (e-mail: a.benito.fisioterapia@gmail.com).
}

Rev Fisioter Invasiva 2020;3:45-48.

\begin{abstract}
Keywords

- musculoskeletal ultrasound

- external occipital protuberance exostosis

- invasive physiotherapy

Introduction The current lifestyle, related to the indiscriminate use of screens from early ages with sustained postures, can cause structural changes (osteophytes) to the upper trapezius enthesis on the external occipital protuberance. Such findings in the skull are rare and usually asymptomatic, especially in young adults. Therefore, it is important to analyze, evaluate and correlate these findings with the patient's symptoms. Musculoskeletal ultrasound is an ideal tool to enable the evaluation of these structural alterations. Description of the Exam Prone position avoiding craniocervical hyperextension. A linear probe is used with a low frequency range (8-10 Mhz) The scan used as a reference is the transverse exam of the bone prominence. Subsequently, this is confirmed with a longitudinal exam, which is used to measure the osteophyte. The normal reference value is $<10 \mathrm{~mm}$. Discussion The ultrasound exam described above enables the easily reproducible assessment and measurement of osteophytes and insertional soft tissue at this level to enhance treatment planning.
\end{abstract}

\section{Introduction}

The main purpose of an enthesis is the homogeneous distribution of loads, via the interwoven fibers that form the same, at the exact site where capsules, ligaments or tendons are attached to the bone. Therefore, the enthesis absorbs a great amount of mechanical stress at the insertion. The formation of osteophytes at the enthesis or attachment of the tendon to the bone is multifactorial, as it can be the result of genetic, biomechanical and/or immunological factors. ${ }^{1,2}$ The appearance of the same is not exclusive to the extremities, however, it is also possible to find entheses in the axial skeleton, these commonly respond to aging processes, and therefore are

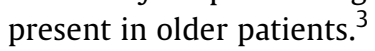

Typically, the diagnosis and visualization is performed based on radiographic studies ( - Fig. 1 ) and because of their slow development over time, they are rarely observed in young adults. ${ }^{3}$ In the scientific literature, many studies have analyzed

received

March 28, 2020

accepted

April 29, 2020
DOI https://doi.org/

10.1055/s-0040-1712928. ISSN 2386-4591. the incidence and symptomatological relationship of osteophyte growth in limb entheses related to defective load distribution. ${ }^{4-6}$ In contrast, the evidence corresponding to the presence of osteophytes in the enthesis in the axial skeleton is not only attributed to defective traction or compression forces, but also to non-mechanical causes. ${ }^{7}$ The current scientific literature concerning possible osteophytes present in the skull is very scarce. Shahar et cols ${ }^{8}$ describe the differences and/or implications that the growth of osteophytes may have at the level of the external occipital protuberance (EOP) among young adults. Although it appears to be asymptomatic, it is likely that an increase in the size of these osteophytes may exacerbate symptoms with aging.

Currently, the use of ultrasound is undergoing constant progress and development in the field of physiotherapy, considered as a very important tool at a clinical level both for physiotherapy assessment and diagnosis, as well as for treatment and subsequent monitoring, as it provides the
Copyright @ 2020 by Thieme Revinter Publicações Ltda, Rio de Janeiro, Brazil
License terms

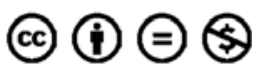




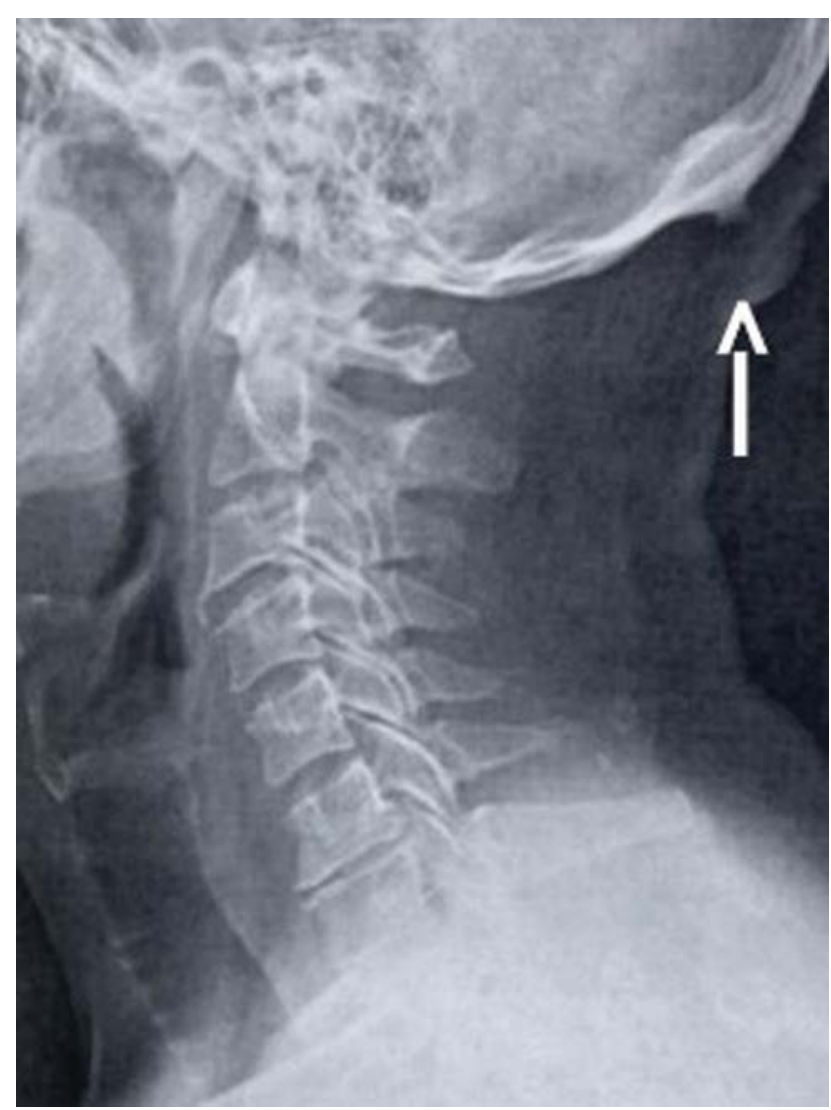

Fig. 1 Radiological study of exostosis on the external occipital protuberance.

physiotherapist with a dynamic, objective, fast, effective and real time study of the neuromusculoskeletal system. ${ }^{9}$

Therefore, the main aim of this study was to describe the ideal exam protocol for the ultrasound identification and evaluation of osteophytes on the enthesis of the upper trapezius muscle on the SOP, and to analyze the possible clinical implications.

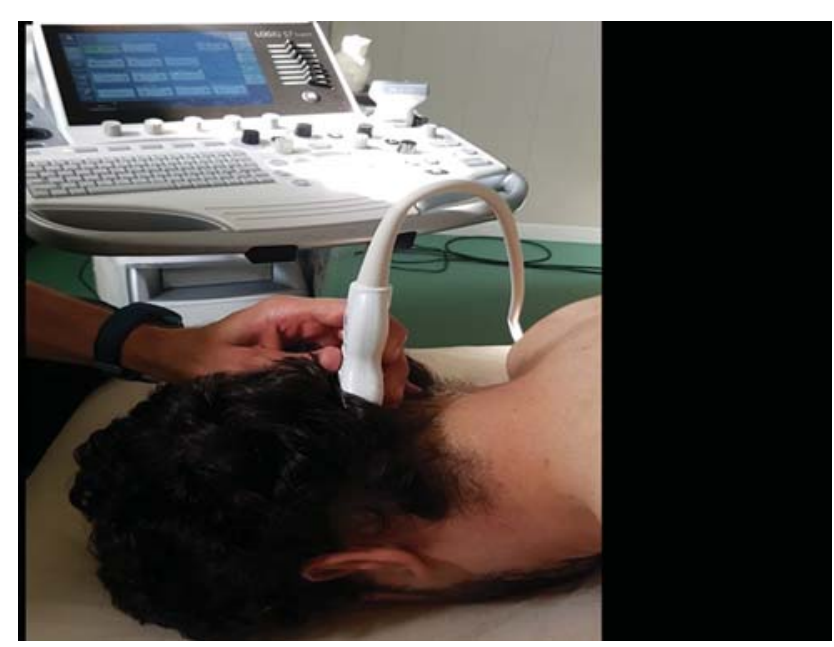

Fig. 2 Ideal position for patient examination and ultrasound probe. Cross sectional scan used as a reference.

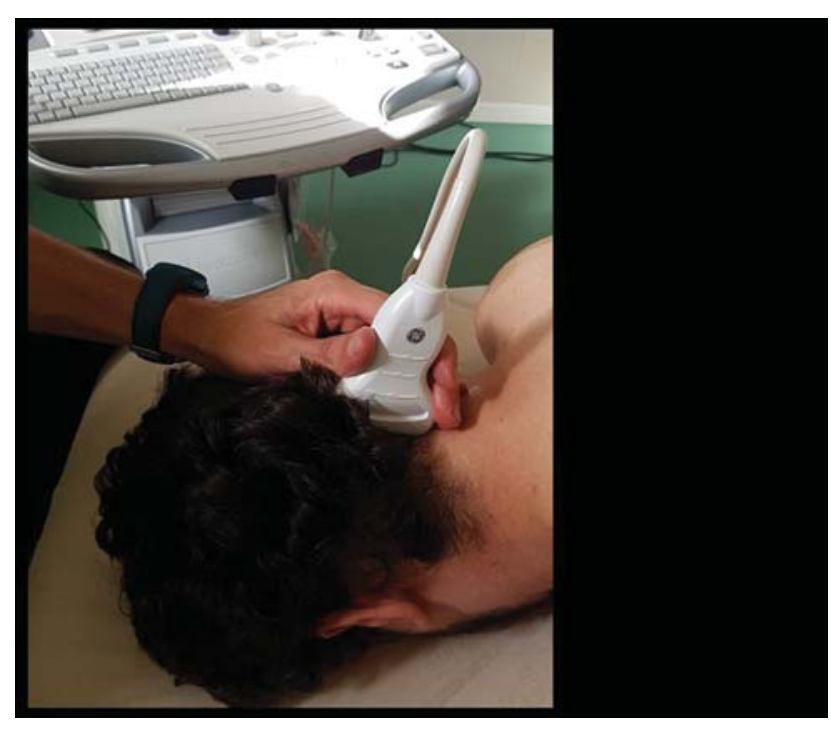

Fig. 3 Position of the probe in the longitudinal section of reference for evaluation and measurement.

\section{Scan Description}

\section{Patient Position}

The patient is placed in prone lying with a comfortable position of the neck, using the face hole of the treatment table, avoiding cranio-cervical hyperextension, which hinders access to the EOP, enabling optimal contact of the probe. (-Fig. 2).

\section{Image Optimization}

A linear probe is recommended with a low frequency range $(8-10 \mathrm{Mhz})$, which is variable depending on the patient's subcutaneous cell tissue and muscle volume. The reference section will be transversal to the axial axis, identifying a bony prominence, the EOP, which generates a posterior acoustic shadow (-Fig. 3). The location is confirmed with a section that is longitudinal to the axial axis of the body, to visualize the proximal EOP and the entheses and the fibers of the upper trapezius muscle arranged in a caudal direction. This is the section of choice for assessment and measurement. With the proximal end of the probe, the EOP is located and, distally, the proximal tendon insertion of the upper trapezius is visualized in a longitudinal projection ( - Fig. 4).

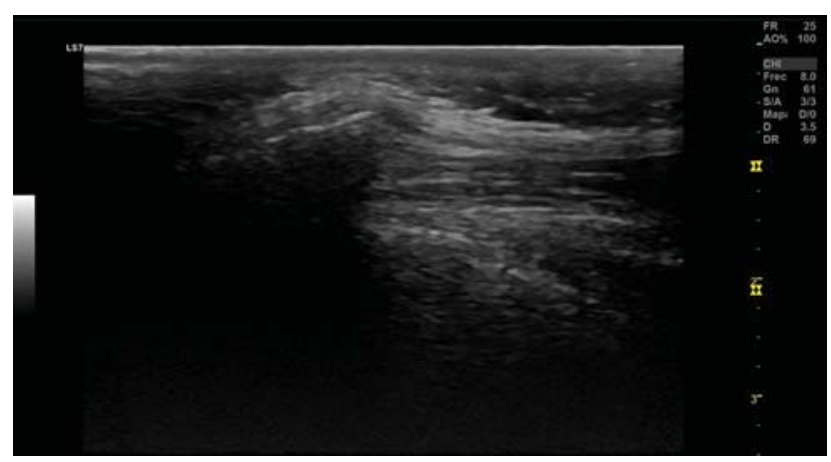

Fig. 4 Longitudinal ultrasound section, the reference used for assessment and measurement. 
It is possible to assess and quantify the distance by measuring from the inion to the most distal end of the possible exostosis. Based on the existing evidence, ${ }^{8} 5 \mathrm{~mm}$ is established as the minimum threshold for the measurement of the exostosis, whereas $10 \mathrm{~mm}$ is the threshold for its classification as an extended exostosis.

\section{Discussion}

As shown in the study by Shahar et $\mathrm{al}^{8}{ }^{8}$ the finding of osteophytes in the EOP by means of X-rays is increasingly frequent in daily clinical practice, with an incidence of $41 \%$, affecting over $67 \%$ of men and $20 \%$ of women. Studies concerning cervical exostosis of the EOP are scarce and can be classified into radiological or anatomical studies. ${ }^{10}$ Assessment using musculoskeletal ultrasound allows greater immediacy and precision in the observation of possible osteophytes at the level of the EOP. The scientific literature describes different points of view regarding the cause behind the appearance of these exostoses, however, both the reduced number of samples used and the absence of relevant data on trauma, causative diseases, postural and occupational relationships, do not allow us to draw valid conclusions regarding the prevalence and cause of exostosis at the level of the EOP. Marshall et $\mathrm{al}^{10}$ consider this as being an anatomical variant in late adolescence due to growth in puberty, generating exostoses due to increased insertion load and sensitivity to palpation in the area. ${ }^{10}$ Moreover, authors such as Benjamin et $\mathrm{al}^{1}$ and McGonagle et $\mathrm{al}^{7}$ consider that these disorders may be due to mechanical factors that cause a physiopathological process in the structure. ${ }^{1,2}$

Scientific Reports Nature Research published an article by Shahar et $\mathrm{al}^{8}$ establishing the main etiology of repetitive traction on this enthesis by prolonged positions of craniocervical flexion. A direct relationship is established with the habitual and prolonged usage of mobiles and tablets. ${ }^{8}$ Due to the extensive media coverage, the authors subsequently published a rectification pointing out the observational nature of the study and therefore, objectively, no direct relationships could be established.

Although major conclusions cannot be drawn with the current evidence available, the young age of the patients in the aforementioned studies means that degenerative factors are most likely ruled out, with excess stress or mechanical load on the enthesis being the possible main cause, as reflected in recent animal studies. ${ }^{11}$ Thus, it is important to consider that without a decrease in mechanical stress in the area of the enthesis, it is also likely that the size of the osteophytes will increase as a natural process of aging. No definitive results or conclusions can be obtained due to the lack of postural and/or ergonomic data.

Considering these findings, in these cases, it would be interesting to observe and determine possible direct relationships with the appearance of these entheses during growth periods in puberty with similar exostoses such as the so-called Osgood-Schlatter disease. In the latter case, these exostoses are located in the anterior tuberosity of the tibia, in which high tension loads in the enthesis are described as the main cause, not necessarily having a direct association with painful symptoms. ${ }^{12}$

The ultrasound finding described in this article may have several implications for clinical practice and for future research. The use of ultrasound will allow a real-time, radiation-free assessment, and can enable measurements and assessments of the bone cortex and possible osteophytes found in the EOP. The clinical experience with ultrasound assessment in other insertional tendon structures, allows us also to infer, in this case, that with musculoskeletal ultrasound it is possible to evaluate the tendon tissue surrounding this exostosis. This tissue which is directly anchored in the enthesis is a source of possible pathologies and associated symptoms.

Likewise, the authors have frequently observed that this finding in the EOP is present in asymptomatic subjects, in line with existing evidence. ${ }^{8}$

The ultrasound finding of this exostosis may indicate that this insertion area of the upper trapezius muscle is a subjective area of high or repetitive mechanical traction. Thus, the ultrasound assessment, always associated to the patient's clinical situation, allows us to evaluate and plan our physiotherapy treatment to include preventive postural measures that could aggravate this finding.

In the field of invasive physiotherapy, ultrasound allows us to objectify the exostosis, enabling professionals to perform, when necessary, invasive interventions in the area (for example with percutaneous needle electrolysis), while exercising caution to avoid direct interventions upon the exostosis, and therefore avoiding irritation of the periosteum.

\section{References}

1 Benjamin M, Rufai A, Ralphs JR. The mechanism of formation of bony spurs (enthesophytes) in the achilles tendon. Arthritis Rheum 2000;43(03):576-583

2 McGonagle D, Stockwin L, Isaacs J, Emery P. An enthesitis based model for the pathogenesis of spondyloarthropathy. additive effects of microbial adjuvant and biomechanical factors at disease sites. J Rheumatol 2001;28(10):2155-2159

3 Matsumoto M, Okada E, Toyama Y, Fujiwara H, Momoshima S, Takahata T. Tandem age-related lumbar and cervical intervertebral disc changes in asymptomatic subjects. Eur Spine J 2013;22 (04):708-713

4 Paolaggi JB, Goutet MC, Strutz P, Siaud JR, Le Parc JM, Auquier L. [Enthesopathy in inflammatory spondyloarthropathy. Incidence, clinical, radiological and anatomical descriptions. Current status of the question. Apropos of 37 cases]. Rev Rhum Mal Osteoartic 1984;51(09):457-462

5 Lehtinen A, Taavitsainen M, Leirisalo-Repo M. Sonographic analysis of enthesopathy in the lower extremities of patients with spondylarthropathy. Clin Exp Rheumatol 1994;12(02):143-148

6 Olivieri I, Barozzi L, Padula A. Enthesiopathy: clinical manifestations, imaging and treatment. Baillieres Clin Rheumatol 1998; 12(04):665-681

7 McGonagle D, Thomas RC, Schett G. Spondyloarthritis: may the force be with you? Ann Rheum Dis 2014;73(02):321-323

8 Shahar D, Sayers MG. A morphological adaptation? The prevalence of enlarged external occipital protuberance in young adults. J Anat 2016;229(02):286-291 
48 Ultrasound assessment of the external occipital protuberance in young adults Benito Domingo, García Godino

9 Valera Garrido F, Minaya Muñoz F. Fisioterapia invasiva. 2ª Ed. Barcelona: Elsevier; 2016. Capítulo 4: Ecografía musculoesquelética en fisioterapia; p. 165-176

10 Marshall RC, Abela C, Eccles S. Painful exostosis of the external occipital protuberance. J Plast Reconstr Aesthet Surg 2015;68 (11):e174-e176
11 Jacques $\mathrm{P}$, McGonagle $\mathrm{D}$. The role of mechanical stress in the pathogenesis of spondyloarthritis and how to combat it. Best Pract Res Clin Rheumatol 2014;28(05):703-710

12 Ducher G, CookJ, Spurrier D, et al. Ultrasound imaging of the patellar tendon attachment to the tibia during puberty: a 12-month followup in tennis players. Scand J Med Sci Sports 2010;20(01):e35-e40 